\title{
An Example of Comparison of Internal Surface Materials for Room Acoustics in Conference Hall
}

\author{
Zuhal Ozcetin \\ Faculty of Fine Arts and Design, Department of Architecture, \\ Siirt University, Siirt, Turkey \\ E-mail: zuhalozcetin@gmail.com \\ Merve Gorkem \\ Mego Consulting Architecture and Engineering Construction Industry and Trade Limited \\ Company, Ankara, Turkey \\ E-mail: mervedogangorkem@gmail.com
}

\begin{abstract}
Conference halls are the places where speeches are made to give information to the community on a subject. Conference rooms are often preferred for presentations, project shows and many other activities. Due to the high number of listeners, the sounds are quite echoing. From these disturbing sounds, audience may be disturbed and the efficiency of the event may be reduced. In such environments, it is very important to regulate the acoustics of the volume and to use material. In this context; in the sample conference hall, the case of untreated perforated wood panels used and the case of currently used perforated gypsum panels, were evaluated and compared with the Odeon simulation program. reverberation time (T30), early decay time (EDT), speech transmisson index (STI),A-weighted sound pressure level (SPL (A)), definition (D50) parameters were evaluated. As a result of the study; perforated gypsum board and perforated wood panel usage in the existing hall; similar results were obtained in terms of volume acoustic parameters.
\end{abstract}

Keywords: Acoustic, room acoustics, conference room.

DOI: $10.7176 / \mathrm{JSTR} / 6-01-02$

\section{Konferans Salonunda Hacim Akustiğine Yönelik İç Yüzey Malzeme Karşılaştırmasına Bir Örnek}

\begin{abstract}
Özet
Konferans salonları, topluluğa bir konu üzerinde bilgi vermek amacıyla yapılan konuşmaların yapıldığı mekânlardır. Sunu, proje gösterisi ve çok daha farklı faaliyetler için konferans salonları sıklıkla tercih edilmektedir. Dinleyicinin fazla olması nedeniyle sesler, oldukça yankılı çıkar. Rahatsız edici duruma gelen bu seslerden, kişiler rahatsız olabilir ve etkinliğin verimliliği düşebilir. Bu tür ortamlarda hacmin akustiğinin düzenlenmesi ve bununla birlikte malzeme kullanımı oldukça önemlidir. Bu kapsamda bu çalışmada; örnek konferans salonunda uygulanmamış perfore ahşap panellerin kullanıldığ 1 durum ile mevcut durumda kullanılmış perfore alçı panellerin kullanıldığı durum, Odeon simülasyon programı ile değerlendirilmiş ve karşılaştırmaları yapılarak, malzeme farklılığı açısından, reverberasyon süresi $\left(\mathrm{T}_{30}\right)$, erken sönümlenme süresi (EDT), konuşmanın iletim indeksi (STI), A-ağırlıklı ses basınç seviyesi (SPL(A)), konuşmanın belirginliği ( $\left.\mathrm{D}_{50}\right)$ parametrelerinin performansları değerlendirilmiştir. Çalışmanın sonucunda; mevcut salonda uygulanan perfore alçı panel levha ile perfore ahşap panel kullanım durumları değerlendirildiğinde; hacim akustiği parametreleri bakımından birbirine yakın sonuçlar elde edilmiştir.
\end{abstract}

Anahtar Kelimeler: Akustik, hacim akustiği, konferans salonu.

12 | P a g e

www.iiste.org 


\section{Giriş}

Günümüzde, teknolojinin gelişmesi ile birlikte binalarda; aydınlatma, akustik, iklimlendirme, enerji ve yangın güvenliği gibi konularda, ihtiyaç duyulan konfor düzeyi giderek artmaktadır. Akustik biliminin tarihsel gelişimi incelendiğinde, tüm dünyada hacim akustiği alanında çalışan araştırmacıların amacının; mimari tasarım parametrelerinin, hacimlerin akustik performansına etkisinin tespit edilmesine yönelik olduğu görülmektedir. Bunun yanında son zamanlarda literatürde, tasarım parametrelerinin yanı sıra kullanılan yapı malzemelerinin de akustik performansa etkisi, araştırma konuları içerisinde yer almaktadir.

Akustik konforun önem kazandığı hacimlerde, mimari tasarım sürecinde alınan tasarım kararları, malzeme seçimi gibi etmenler hacimlerin akustik performansı üzerinde oldukça etkilidir. Malzeme seçimi konusunda akustik uzman görüşü istenmesinin yanında, malzeme bilgisinin olması ve önerilecek malzemelerin performansının bilinmesi, özellikle kullanılan simülasyon programlarına veri girişi için önemlidir. Bunun yanında malzemelerin mekân içinde gösterdiği performansın bilinmesi, sonraki çalışmalara ışık tutması açısından değerlidir.

Ölçüm yönteminin her mekan ve durumda yapılamadığı koşullarda simülasyon programları ile değerlendirme yapılması gerekmektedir. Teknolojinin ilerlemesi ile birlikte simülasyon programlarının güvenilirliği artmıştır.

Bu kapsamda çalışmada, incelenen Konferans Salonu için; projede yer alan ve uygulanmamış olan perfore ahşap panellerin kullanıldığı durum ile mevcut durumda uygulanmış perfore alçı panellerin kullanıldığı durum değerlendirilmiş ve karşılaştırmaları yapılmıştır. Odeon simülasyon programı ile malzeme farklılı̆̆ değerlendirildiğinde, reverberasyon süresi $\left(\mathrm{T}_{30}\right)$, erken sönümlenme süresi (EDT), konuşmanın iletim indeksi (STI), A-ağırlıklı ses basınç seviyesi (SPL(A)), konuşmanın belirginliği ( $\left.D_{50}\right)$ parametreleri incelenmiş ve hacim akustiğine yönelik olarak yapılan analizler ışığında; konferans salonunun ülkemizde yürürlükte olan yönetmelikler ve uluslararası standartlara göre analizi yapılmıştır.

\section{Yöntem}

Konuşmanın anlaşılabilirliğinin sağlanması ve yankı gibi akustik problemlerin önlenmesi konferans işlevli hacim akustiği analizleri için önemlidir. Bu kapsamda çalışmada yöntem olarak; konuşma işlevi için ihtiyaç duyulan akustik koşulların, hacim akustiğine yönelik analizleri için, ODEON (V 15.14 Auditorium) hacim akustiği simülasyon programı kullanılmıştır [1]. Ülkemizde yürürlükte olan yönetmelikler ve uluslararası standartlara göre; elde edilen veriler iki malzeme için konferans salonunda değerlendirilmiştir.

3. Konferans Salonu İç Yüzey Malzemeleri ile Akustik Simülasyon Sonuçları ve Değerlendirilmesi Eğitim binası konferans salonunda karşılaştırması yapılacak olan perfore ahşap panel ve perfore alçı panel kullanımına göre, ayrı ayrı yapılan değerlendirmeler ve kıyaslamalar; reverberasyon süresi $\left(\mathrm{T}_{30}\right)$, erken sönümlenme süresi (EDT), konuşmanın iletim indeksi (konuşmanın anlaşılabilirliği) (STI), Aağırlıklı ses basınç seviyesi (SPL(A)), konuşmanın belirginliği $\left(\mathrm{D}_{50}\right)$ parametreleri doğrultusunda yapılmıştır. Salon içerisinde kullanılan malzemelerin ses yutma katsayıları çizelge 1'de verilmiştir.

Çizelge 1. Kullanılan malzemelerin ses yutma katsayıları

\begin{tabular}{|c|c|c|c|c|c|c|c|c|}
\hline \multirow{2}{*}{ NO } & \multicolumn{8}{|c|}{ Ses Yutma Katsayıları (Sound Absorption Coefficients) [6] } \\
\hline & $63 \mathrm{~Hz}$ & $125 \mathrm{~Hz}$ & $250 \mathrm{~Hz}$ & $500 \mathrm{~Hz}$ & $1000 \mathrm{~Hz}$ & $2000 \mathrm{~Hz}$ & $4000 \mathrm{~Hz}$ & $8000 \mathrm{~Hz}$ \\
\hline \multirow{2}{*}{3002} & \multicolumn{8}{|c|}{ SALON DÖȘEME: Ahșap parke } \\
\hline & 0.04000 & 0.04000 & 0.04000 & 0.07000 & 0.06000 & 0.06000 & 0.07000 & 0.07000 \\
\hline \multirow{2}{*}{3004} & \multicolumn{8}{|c|}{ SAHNE DÖŞEME: Ahşap parke (kadronajlı) } \\
\hline & 0.15000 & 0.15000 & 0.11000 & 0.11000 & 0.07000 & 0.06000 & 0.07000 & 0.07000 \\
\hline \multirow{2}{*}{11009} & \multicolumn{8}{|c|}{ SALON İZLEYİCİ: Hafif yoğunluklu, kolçaklı koltuk (izleyicili) } \\
\hline & 0.51000 & 0.51000 & 0.64000 & 0.75000 & 0.80000 & 0.82000 & 0.83000 & 0.83000 \\
\hline \multirow{2}{*}{10005} & \multicolumn{8}{|c|}{ SALON CAM YÜZEYLER: Lamine cam } \\
\hline & 0.18000 & 0.18000 & 0.06000 & 0.04000 & 0.03000 & 0.02000 & 0.02000 & 0.02000 \\
\hline \multirow{2}{*}{10007} & \multicolumn{8}{|c|}{ SALON KAPILAR: Ahşap kapı } \\
\hline & 0.14000 & 0.14000 & 0.10000 & 0.06000 & 0.08000 & 0.10000 & 0.10000 & 0.10000 \\
\hline
\end{tabular}


Salonun üç boyutlu simülasyon modeli yapılarak, ODEON programına aktarılmış ve malzeme değişikliği sonucu oluşan akustik tasarımların analizleri elde edilmiştir (Şekil 1). Elde edilen verilerin, ülkemiz yönetmelik, ulusal ve uluslararası mevzuatlar ile karşılaştırmaları yapılarak, değerlendirilmiştir.

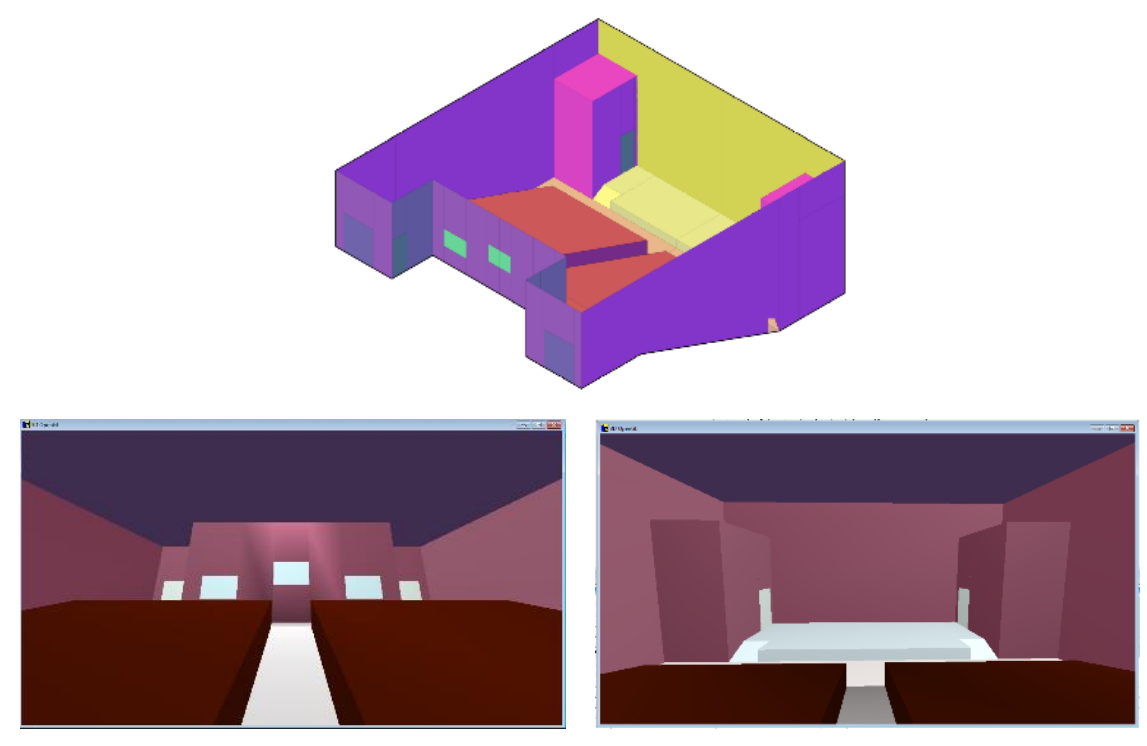

Şekil 1. Konferans Salonu - 3 boyutlu görselleri

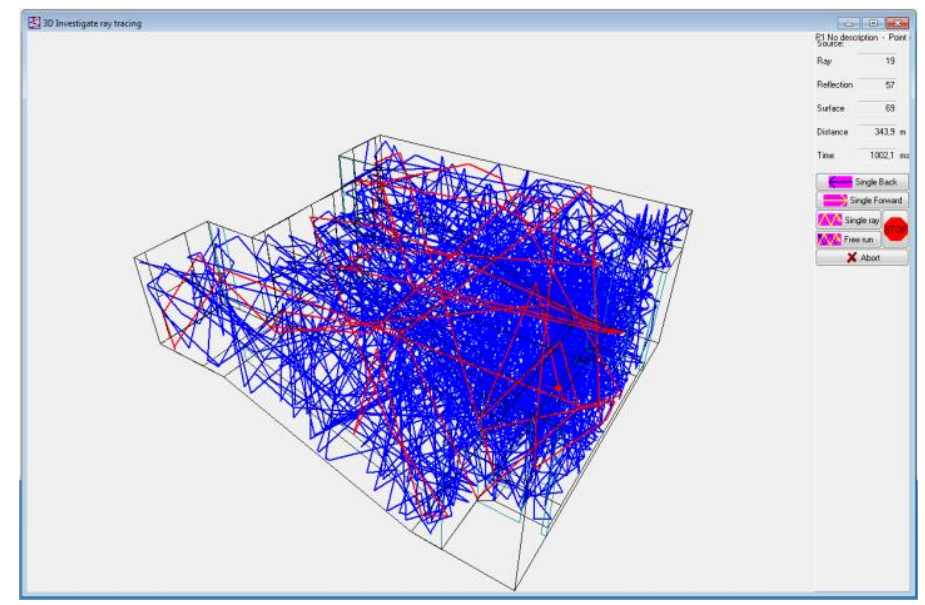

Şekil 2. Konferans Salonu - hacim içi yansıyan seslerin ışın analizi 


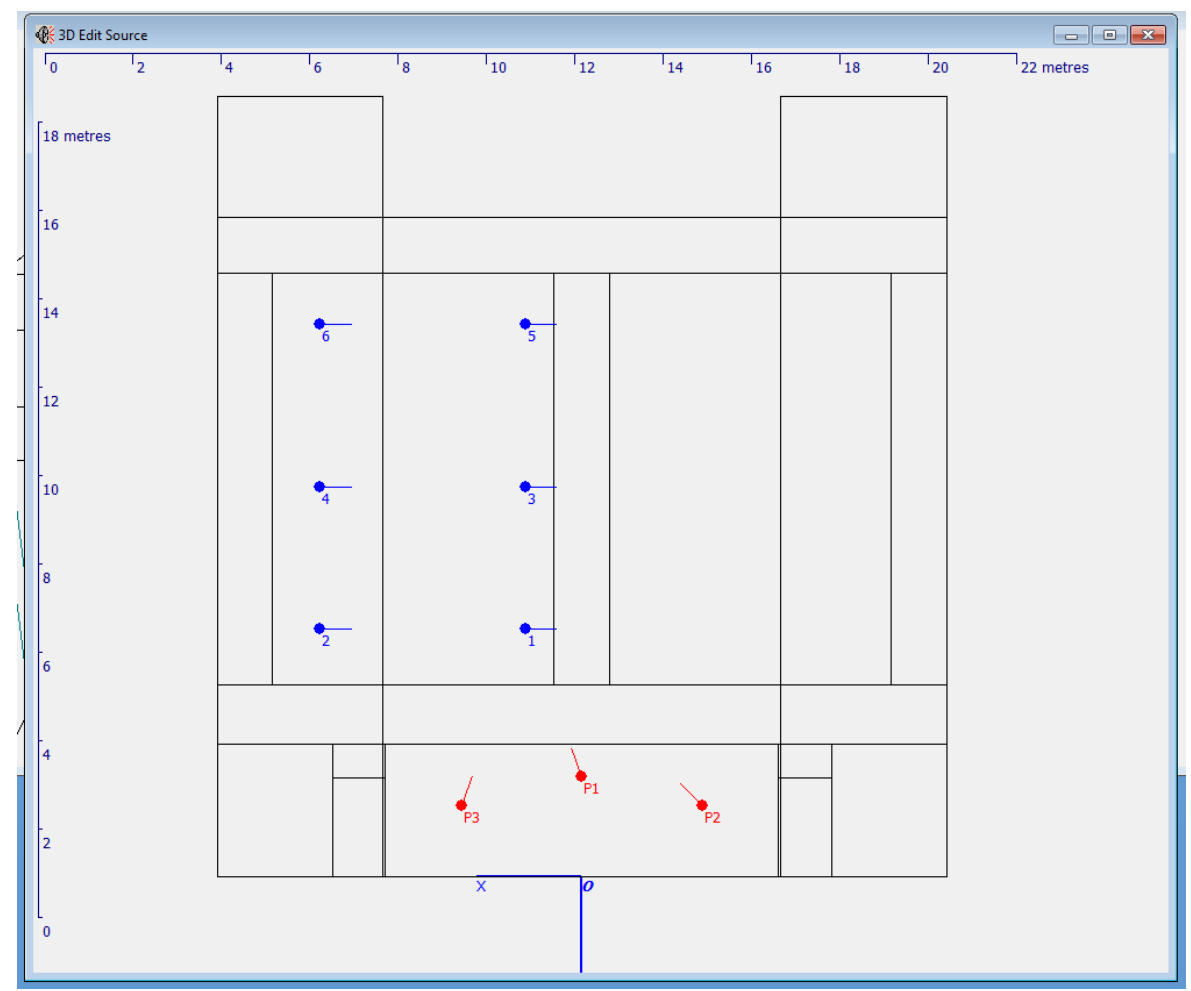

Şekil 3. Konferans Salonu - kaynak ve alıcı konumları - plan

Konferans salonunda, standartlara uygun olarak sahnede 3 kaynak noktası, salon içerisinde 6 alıcı noktası belirlenmiştir (Şekil 3).

\subsection{Perfore Ahşap Paneller ile Yapılan Analiz}

Konferans salonu projesinde yer alan ve yerinde uygulanmamış olan perfore ahşap panellerin özellikleri aşağıda verilmiştir:

- Tam Delikli Ahşap Panel: $18 \mathrm{~mm}$ MDF/Lam, delik çapı $8 \mathrm{~mm}$ ve delik merkezleri aks aralığ $32 \mathrm{~mm} * 32 \mathrm{~mm}$ 'dir. Arkasında $0.2 \mathrm{~mm}$ akustik bez ve $4 \mathrm{~cm}$ kalınlığında $50 \mathrm{~kg} / \mathrm{m}^{3}$ yoğunluğunda taş yünü uygulanmıştır.

- Kanallı Ahşap Panel: $18 \mathrm{~mm}$ MDF/Lam, delik çap1 $8 \mathrm{~mm}$ ve delik merkezleri aks aralığ 16 mm*32 mm'dir. Panelin salona bakan ön yüzünde boşluk genişliği $4 \mathrm{~mm}$ olan kanallar bulunacaktır. Arkasında $0.2 \mathrm{~mm}$ akustik bez ve $4 \mathrm{~cm}$ kalınlığında $50 \mathrm{~kg} / \mathrm{m}^{3}$ yoğunluğunda taş yünü uygulanmıştır.

Çizelge 2. Kullanılan perfore ahşap panellerin ses yutma katsayıları

\begin{tabular}{|c|c|c|c|c|c|c|c|c|}
\hline \multirow{2}{*}{ NO } & \multicolumn{8}{|c|}{ Ses Yutma Katsayıları (Sound Absorption Coefficients) [6] } \\
\hline & $63 \mathrm{~Hz}$ & $125 \mathrm{~Hz}$ & $250 \mathrm{~Hz}$ & $500 \mathrm{~Hz}$ & $1000 \mathrm{~Hz}$ & $2000 \mathrm{~Hz}$ & $4000 \mathrm{~Hz}$ & $8000 \mathrm{~Hz}$ \\
\hline \multirow{2}{*}{14314} & \multicolumn{8}{|c|}{$\begin{array}{l}\text { SALON ASMA TAVAN (YUTUCU): } 18 \mathrm{~mm} \text { MDF/Lam kaplama (delikli) + Akustik kumaş 0,2 mm + } \\
\text { Taşyünü } 40 \mathrm{~mm}\left(50 \mathrm{~kg} / \mathrm{m}^{3}\right)\end{array}$} \\
\hline & ------ & 0.34000 & 0.62000 & 0.58000 & 0.49000 & 0.36000 & 0.25000 & 0.31000 \\
\hline \multirow[t]{2}{*}{14315} & \multirow{2}{*}{\multicolumn{8}{|c|}{$\begin{array}{l}\text { SALON DUVAR YÜZEYLERİ (YUTUCU): } 18 \mathrm{~mm} \text { MDF/Lam kaplama (kanallı-delikli) + Akustik kumas } \\
0,2 \mathrm{~mm}+\text { Taşyünü } 40 \mathrm{~mm}\left(50 \mathrm{~kg} / \mathrm{m}^{3}\right)\end{array}$}} \\
\hline & & & 0.68000 & 0.66000 & 0.60000 & 0.50000 & 0.52000 & 0.61000 \\
\hline
\end{tabular}


International Journal of Scientific and Technological Research

ISSN 2422-8702 (Online), DOI: 10.7176/JSTR/6-01-02

Vol.6, No.01, 2020

IISE

\section{$\underline{\text { Reverberasvon Süresi Parametresi }\left(T_{30}\right)}$}

Çizelge 3. Perfore ahşap panel için 6 alıcı noktasında reverberasyon süresi parametresinin değerleri

\begin{tabular}{|c|c|c|c|c|c|c|c|c|}
\hline $\mathbf{T}_{\mathbf{3} 0}$ & $\mathbf{6 3} \mathbf{~ H z}$ & $\mathbf{1 2 5} \mathbf{~ H z}$ & $\mathbf{2 5 0} \mathbf{~ H z}$ & $\mathbf{5 0 0} \mathbf{~ z z}$ & $\mathbf{1 0 0 0} \mathbf{~ H z}$ & $\mathbf{2 0 0 0} \mathbf{H z}$ & $\mathbf{4 0 0 0} \mathbf{H z}$ & $\mathbf{8 0 0 0} \mathbf{~ H z}$ \\
\hline $\mathbf{1}$ & 0,68 & 0,69 & 0,35 & 0,35 & 0,38 & 0,48 & 0,50 \\
\hline $\mathbf{2}$ & 0,68 & 0,70 & 0,33 & 0,33 & 0,37 & 0,47 & 0,36 \\
\hline $\mathbf{3}$ & 0,69 & 0,70 & 0,33 & 0,33 & 0,37 & 0,47 & 0,48 & 0,35 \\
\hline $\mathbf{4}$ & 0,71 & 0,73 & 0,33 & 0,33 & 0,37 & 0,46 & 0,48 & 0,34 \\
\hline $\mathbf{5}$ & 0,67 & 0,69 & 0,33 & 0,33 & 0,37 & 0,46 & 0,46 & 0,34 \\
\hline $\mathbf{6}$ & 0,66 & 0,67 & 0,32 & 0,32 & 0,36 & 0,44 & 0,45 & 0,33 \\
\hline
\end{tabular}

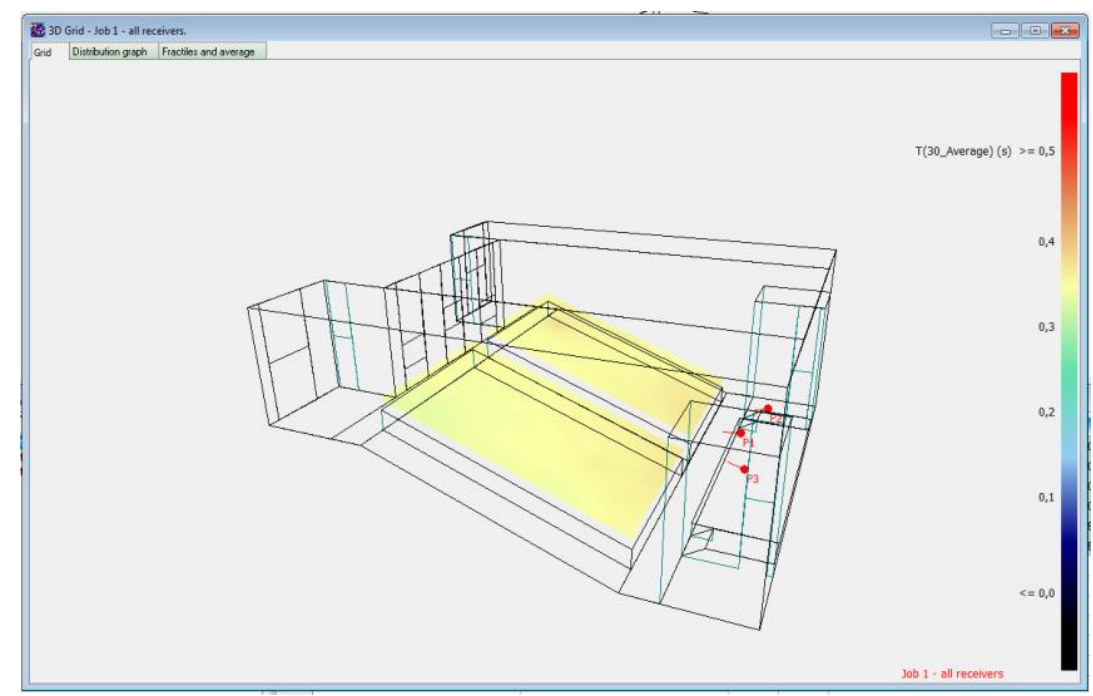

Şekil 4. Konferans salonu - reverberasyon süresi $\left(\mathrm{T}_{30}\right)$ parametresinin dağılımı (ortalama)

\section{Erken Sönümlenme Süresi Parametresi (EDT)}

Çizelge 4. Perfore ahşap panel için 6 alıcı noktasında erken sönümlenme süresi parametresinin değerleri

\begin{tabular}{|c|c|c|c|c|c|c|c|c|}
\hline $\mathbf{E D T}$ & $\mathbf{6 3} \mathbf{H z}$ & $\mathbf{1 2 5} \mathbf{H z}$ & $\mathbf{2 5 0} \mathbf{~ H z}$ & $\mathbf{5 0 0} \mathbf{H z}$ & $\mathbf{1 0 0 0} \mathbf{~ H z}$ & $\mathbf{2 0 0 0} \mathbf{H z}$ & $\mathbf{4 0 0 0} \mathbf{H z}$ & $\mathbf{8 0 0 0} \mathbf{H z}$ \\
\hline $\mathbf{1}$ & 0,70 & 0,71 & 0,21 & 0,24 & 0,28 & 0,39 & 0,40 \\
\hline $\mathbf{2}$ & 0,72 & 0,73 & 0,28 & 0,30 & 0,34 & 0,45 & 0,46 \\
\hline $\mathbf{3}$ & 0,67 & 0,68 & 0,30 & 0,31 & 0,34 & 0,42 & 0,31 \\
\hline $\mathbf{4}$ & 0,69 & 0,70 & 0,28 & 0,29 & 0,34 & 0,43 & 0,42 & 0,31 \\
\hline $\mathbf{5}$ & 0,60 & 0,61 & 0,26 & 0,28 & 0,30 & 0,36 & 0,36 & 0,27 \\
\hline $\mathbf{6}$ & 0,65 & 0,66 & 0,28 & 0,28 & 0,32 & 0,39 & 0,38 & 0,28 \\
\hline
\end{tabular}

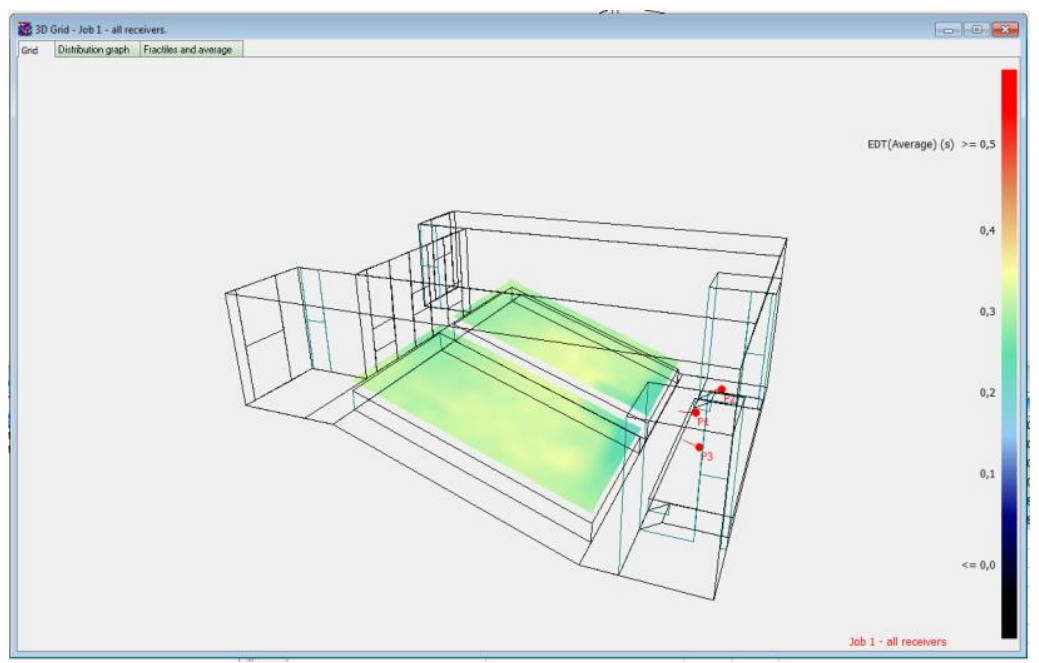

Şekil 5. Konferans salonu - erken sönümlenme süresi (EDT) parametresinin dağılımı $(500 \mathrm{~Hz})$ 
International Journal of Scientific and Technological Research

ISSN 2422-8702 (Online), DOI: 10.7176/JSTR/6-01-02

Vol.6, No.01, 2020

\section{$\underline{A \text { - Ăğrllklı Ses Basinc Sevivesi Parametresi (SPL (A))) }}$}

Çizelge 5. Perfore ahşap panel için 6 alıcı noktasında A-ağılıklı ses basınç seviyesi parametresinin değerleri

\begin{tabular}{|c|c|}
\hline SPL (A) & \\
\hline $\mathbf{1}$ & 60,7 \\
\hline $\mathbf{2}$ & 58,2 \\
\hline $\mathbf{3}$ & 57,7 \\
\hline $\mathbf{4}$ & 56,6 \\
\hline $\mathbf{5}$ & 55,9 \\
\hline $\mathbf{6}$ & 55,3 \\
\hline
\end{tabular}

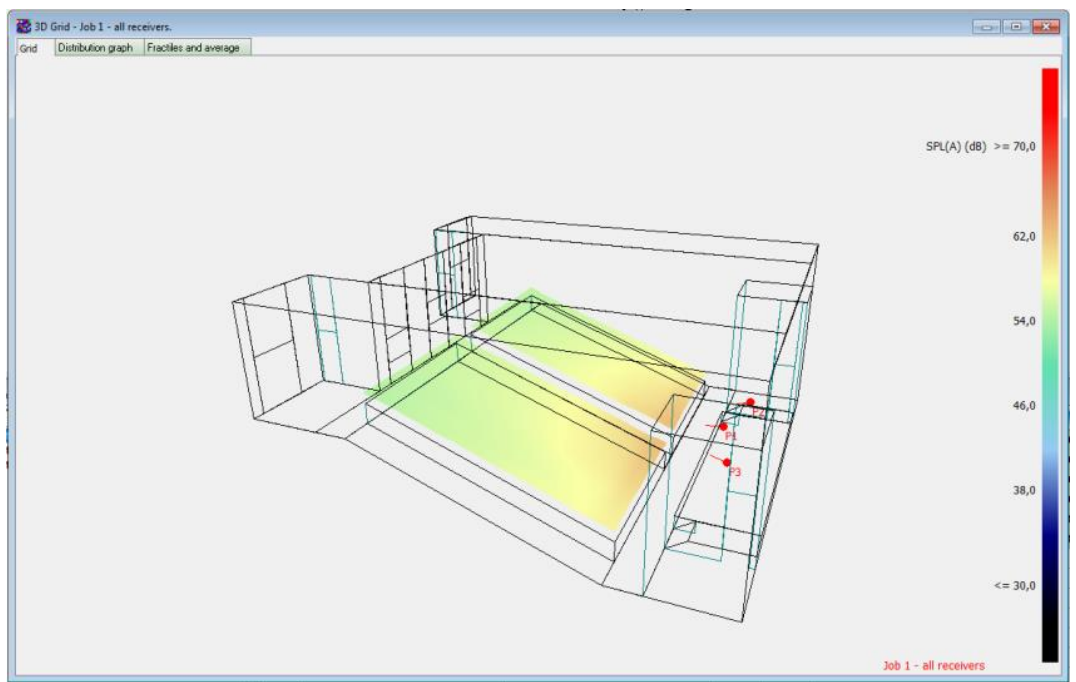

Şekil 6. Konferans Salonu - A-ağırlıklı ses basınç seviyesi (SPL(A)) parametresinin dağılımı

\section{$\underline{\text { Konussmanin Iletim Indeksi Parametresi (STI) }}$}

Çizelge 6. Perfore ahşap panel için 6 alıcı noktasında konuşmanın iletim indeksi parametresinin değerleri

\begin{tabular}{|c|c|}
\hline STI & \\
\hline $\mathbf{1}$ & 60,7 \\
\hline $\mathbf{2}$ & 58,2 \\
\hline $\mathbf{3}$ & 57,7 \\
\hline $\mathbf{4}$ & 56,6 \\
\hline $\mathbf{5}$ & 55,9 \\
\hline $\mathbf{6}$ & 55,3 \\
\hline
\end{tabular}

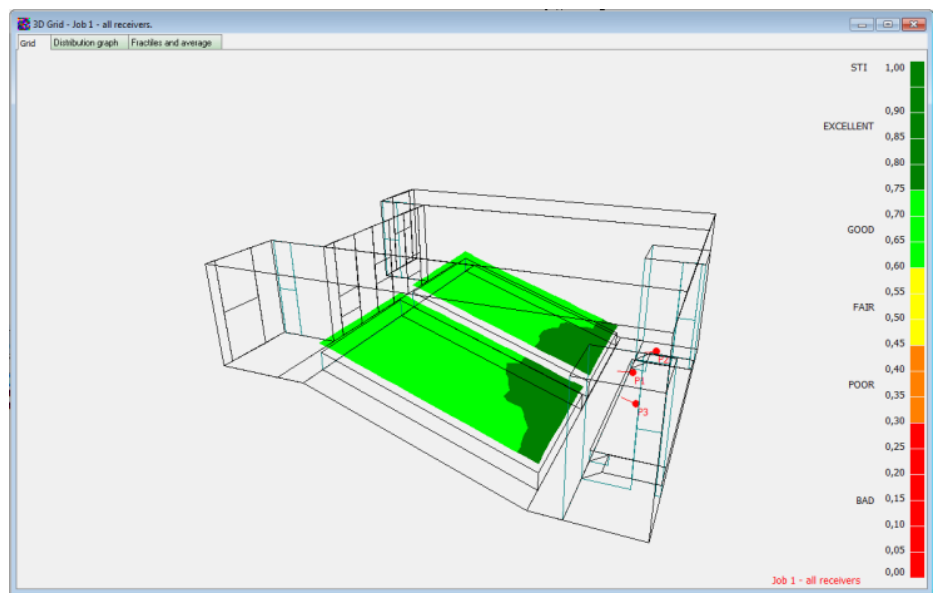

Şekil 7. Konferans Salonu - konuşmanın iletim indeksi (STI) parametresinin dağılımı 
International Journal of Scientific and Technological Research

ISSN 2422-8702 (Online), DOI: 10.7176/JSTR/6-01-02

Vol.6, No.01, 2020

\section{Konusmanın Belirginliği Parametresi (D50)}

Çizelge 7. Perfore ahşap panel için 6 alıcı noktasında konuşmanın belirginliği parametresi değerleri

\begin{tabular}{|c|c|c|c|c|c|c|c|c|}
\hline $\mathbf{D 5 0}$ & $\mathbf{6 3} \mathbf{~ H z}$ & $\mathbf{1 2 5} \mathbf{~ H z}$ & $\mathbf{2 5 0} \mathbf{~ H z}$ & $\mathbf{5 0 0} \mathbf{~ H z}$ & $\mathbf{1 0 0 0} \mathbf{~ H z}$ & $\mathbf{2 0 0 0} \mathbf{H z}$ & $\mathbf{4 0 0 0} \mathbf{H z}$ & $\mathbf{8 0 0 0} \mathbf{~ H z}$ \\
\hline $\mathbf{1}$ & 0,77 & 0,77 & 0,95 & 0,94 & 0,92 & 0,88 & 0,87 & 0,94 \\
\hline $\mathbf{2}$ & 0,70 & 0,70 & 0,93 & 0,92 & 0,89 & 0,84 & 0,84 & 0,91 \\
\hline $\mathbf{3}$ & 0,69 & 0,69 & 0,92 & 0,92 & 0,89 & 0,83 & 0,83 \\
\hline $\mathbf{4}$ & 0,68 & 0,67 & 0,92 & 0,91 & 0,88 & 0,82 & 0,82 & 0,91 \\
\hline $\mathbf{5}$ & 0,74 & 0,73 & 0,94 & 0,93 & 0,90 & 0,85 & 0,85 & 0,92 \\
\hline $\mathbf{6}$ & 0,70 & 0,69 & 0,93 & 0,92 & 0,89 & 0,83 & 0,84 & 0,92 \\
\hline
\end{tabular}

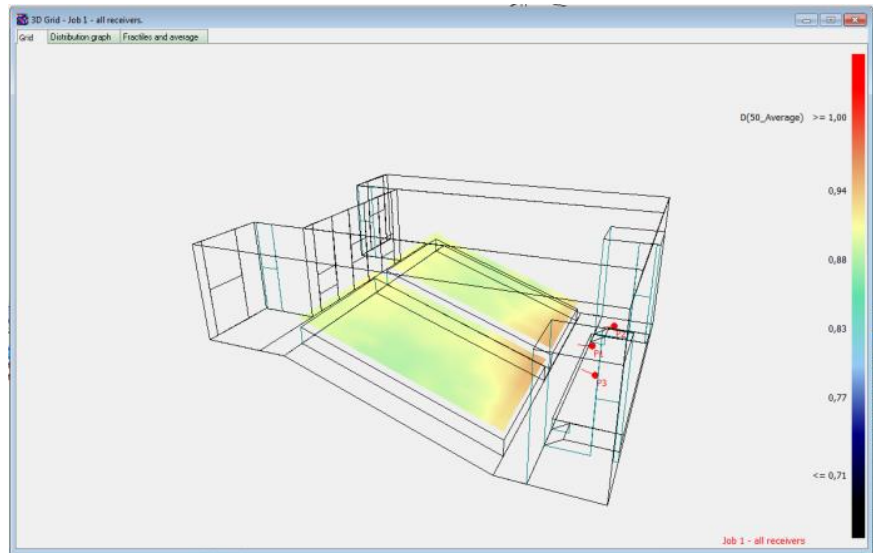

Şekil 8. Konferans Salonu - konuşmanın belirginliği $\left(\mathrm{D}_{50}\right)$ parametresinin dağılımı (ortalama)

Parametrelerin minimum, maksimum ve ortalama değerleri aşağıda verilmiştir.
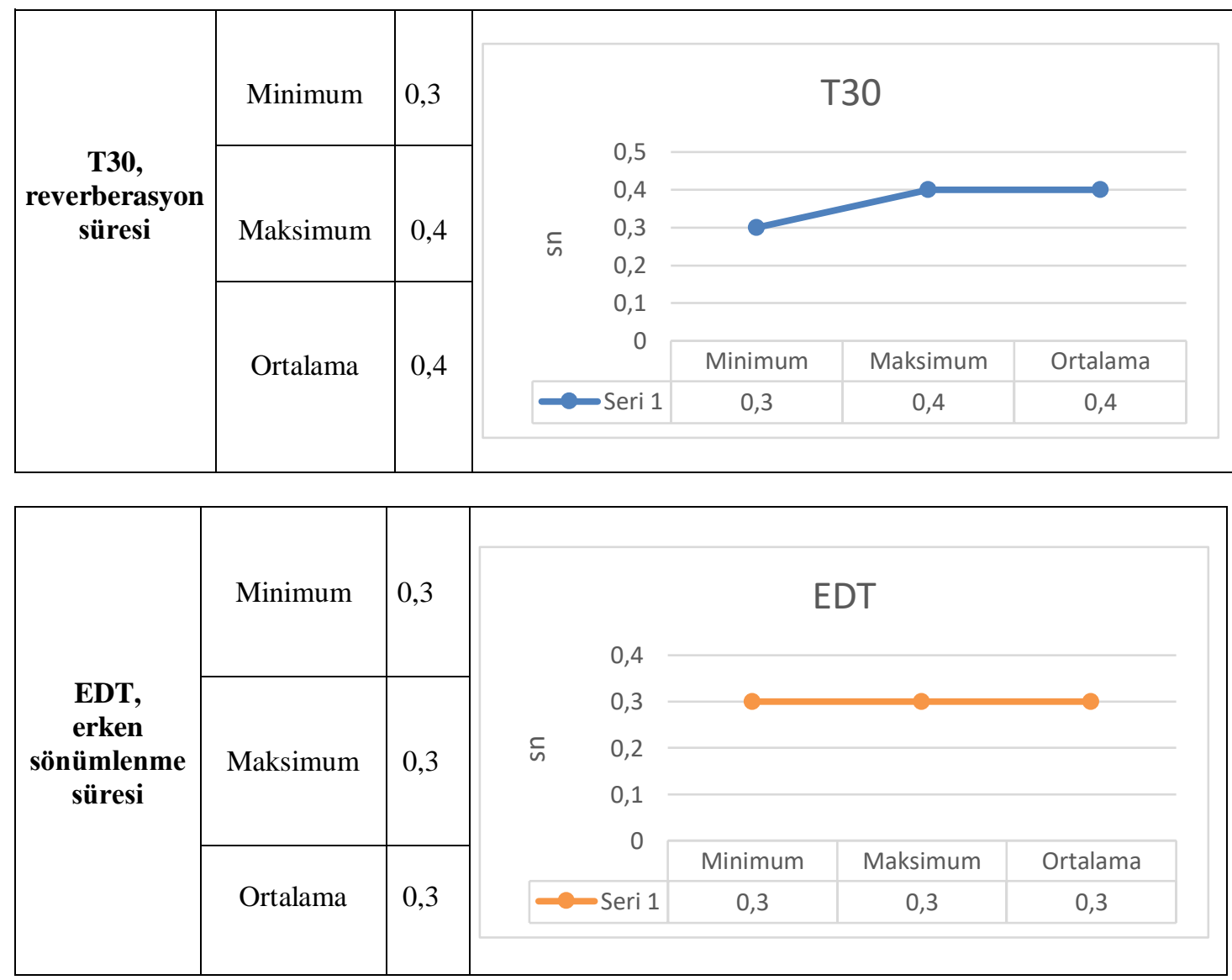

18 | P a g e

www.iiste.org 

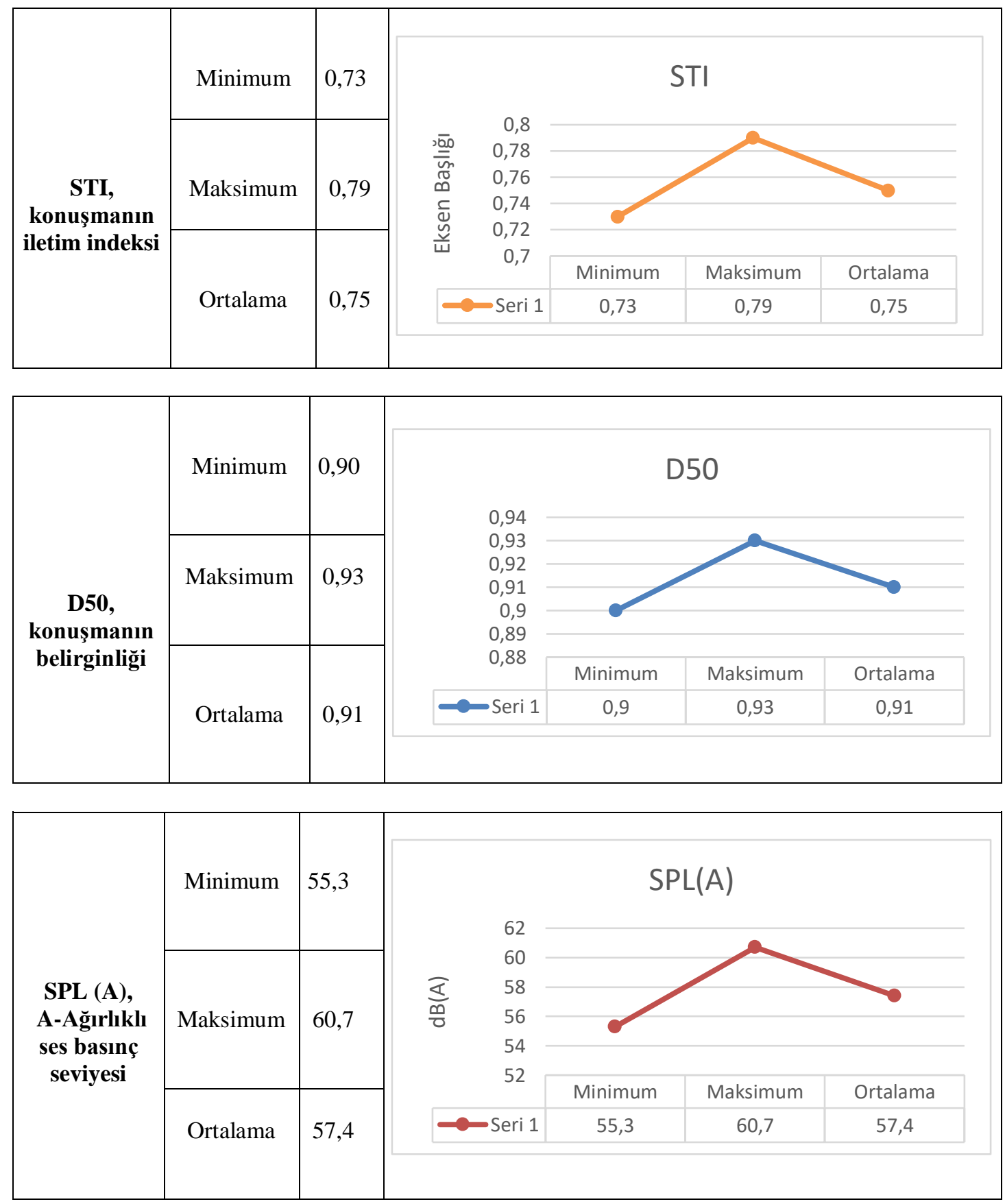

\subsection{Perfore Alçı Paneller ile Yapılan Analiz}

Konferans salonu mevcut durumunda uygulanmış olan perfore alçı panellerin özellikleri aşağıda verilmiştir:

- Perfore Alçı Panel: $12.5 \mathrm{~mm}$ alçı panel, şaşırtmalı dairesel delikli, delik çapları 12 ve $20 \mathrm{~mm}$, delik merkezleri aks aralı̆ 66 mm'dir (12/20/66D). Arkasında $0.2 \mathrm{~mm}$ akustik bez ve $4 \mathrm{~cm}$ kalınlı̆̆ında $50 \mathrm{~kg} / \mathrm{m}^{3}$ yoğunluğunda taş yünü uygulanmıştır. 
Çizelge 8. Kullanılan perfore alçı panellerin ses yutma katsayıları

\begin{tabular}{|c|c|c|c|c|c|c|c|c|}
\hline \multirow{2}{*}{ NO } & \multicolumn{8}{|c|}{ Ses Yutma Katsayıları (Sound Absorption Coefficients) [6] } \\
\hline & $63 \mathrm{~Hz}$ & $125 \mathrm{~Hz}$ & $250 \mathrm{~Hz}$ & $500 \mathrm{~Hz}$ & $1000 \mathrm{~Hz}$ & $2000 \mathrm{~Hz}$ & $4000 \mathrm{~Hz}$ & $8000 \mathrm{~Hz}$ \\
\hline \multirow{2}{*}{14316} & \multicolumn{8}{|c|}{$\begin{array}{l}\text { SALON ASMA TAVAN (YUTUCU): } 12.5 \mathrm{~mm} \text { alçıpanel kaplama (şaşırtmalı dairesel delikli-12/20/66D) } \\
+ \text { Akustik kumaş 0,2 mm + Taşyünü } 40 \mathrm{~mm}\left(50 \mathrm{~kg} / \mathrm{m}^{3}\right)+65 \mathrm{~mm} \text { hava boşluğu }\end{array}$} \\
\hline & ----- & 0.30000 & 0.55000 & 0.80000 & 0.85000 & 0.60000 & 0.65000 & ----- \\
\hline \multirow[t]{2}{*}{14317} & \multicolumn{8}{|c|}{$\begin{array}{l}\text { SALON DUVAR YÜZEYLERİ (YUTUCU): } 12.5 \mathrm{~mm} \text { alçıpanel kaplama (şaşırtmalı dairesel delikli- } \\
\text { 12/20/66D) + Akustik kumaş 0,2 mm + Taşyünü } 40 \mathrm{~mm}\left(50 \mathrm{~kg} / \mathrm{m}^{3}\right)+400 \mathrm{~mm} \text { hava boşluğu }\end{array}$} \\
\hline & ----- & 0.60000 & 0.70000 & 0.70000 & 0.80000 & 0.60000 & 0.65000 & ----- \\
\hline
\end{tabular}

\section{$\underline{\text { Reverberasyon Süresi Parametresi }\left(T_{30}\right)}$}

Çizelge 9. Perfore alçı panel uygulaması için 6 alıcı noktasında reverberasyon süresi parametresinin

\begin{tabular}{|c|c|c|c|c|c|c|c|c|}
\hline $\mathbf{T ( 3 0 )}$ & $\mathbf{6 3} \mathbf{~ H z}$ & $\mathbf{1 2 5} \mathbf{~ H z}$ & $\mathbf{2 5 0} \mathbf{~ H z}$ & $\mathbf{5 0 0} \mathbf{~ H z}$ & $\mathbf{1 0 0 0} \mathbf{~ H z}$ & $\mathbf{2 0 0 0} \mathbf{~ H z}$ & $\mathbf{4 0 0 0} \mathbf{~ H z}$ & $\mathbf{8 0 0 0} \mathbf{~ H z}$ \\
\hline $\mathbf{1}$ & 0,66 & 0,68 & 0,45 & 0,30 & 0,24 & 0,42 & 0,35 \\
\hline $\mathbf{2}$ & 0,66 & 0,69 & 0,44 & 0,30 & 0,23 & 0,41 & 0,31 \\
\hline $\mathbf{3}$ & 0,68 & 0,69 & 0,45 & 0,28 & 0,22 & 0,42 & 0,34 & 0,30 \\
\hline $\mathbf{4}$ & 0,71 & 0,74 & 0,42 & 0,29 & 0,22 & 0,40 & 0,35 & 0,30 \\
\hline $\mathbf{5}$ & 0,67 & 0,69 & 0,43 & 0,28 & 0,22 & 0,41 & 0,35 \\
\hline $\mathbf{6}$ & 0,66 & 0,68 & 0,42 & 0,28 & 0,21 & 0,40 & 0,33 & 0,29 \\
\hline
\end{tabular}

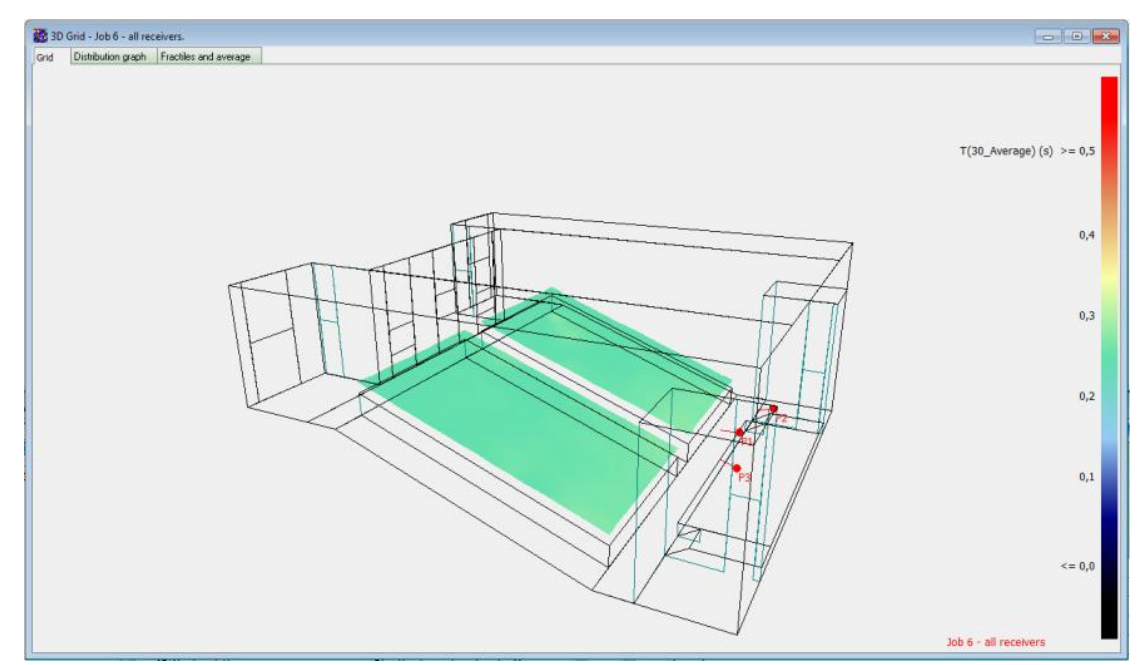

Şekil 9. Konferans Salonu - reverberasyon süresi $\left(\mathrm{T}_{30}\right)$ parametresinin dağılımı (ortalama)

\section{Erken Sönümlenme Süresi Parametresi (EDT)}

Çizelge 10. Perfore alçı panel için 6 alıcı noktasında erken sönümlenme süresi parametresinin değerleri

\begin{tabular}{|c|c|c|c|c|c|c|c|c|}
\hline $\mathbf{E D T}$ & $\mathbf{6 3} \mathbf{~ H z}$ & $\mathbf{1 2 5} \mathbf{~ H z}$ & $\mathbf{2 5 0} \mathbf{~ H z}$ & $\mathbf{5 0 0} \mathbf{~ H z}$ & $\mathbf{1 0 0 0} \mathbf{~ H z}$ & $\mathbf{2 0 0 0} \mathbf{H z}$ & $\mathbf{4 0 0 0} \mathbf{H z}$ & $\mathbf{8 0 0 0} \mathbf{~ H z}$ \\
\hline $\mathbf{1}$ & 0,66 & 0,69 & 0,30 & 0,24 & 0,14 & 0,41 & 0,33 \\
\hline $\mathbf{2}$ & 0,69 & 0,72 & 0,40 & 0,31 & 0,26 & 0,45 & 0,37 \\
\hline $\mathbf{3}$ & 0,68 & 0,70 & 0,39 & 0,33 & 0,29 & 0,43 & 0,32 \\
\hline $\mathbf{4}$ & 0,66 & 0,69 & 0,38 & 0,31 & 0,27 & 0,41 & 0,35 & 0,33 \\
\hline $\mathbf{5}$ & 0,58 & 0,60 & 0,31 & 0,27 & 0,24 & 0,34 & 0,30 & 0,28 \\
\hline $\mathbf{6}$ & 0,63 & 0,65 & 0,35 & 0,25 & 0,20 & 0,35 & 0,31 & 0,28 \\
\hline
\end{tabular}




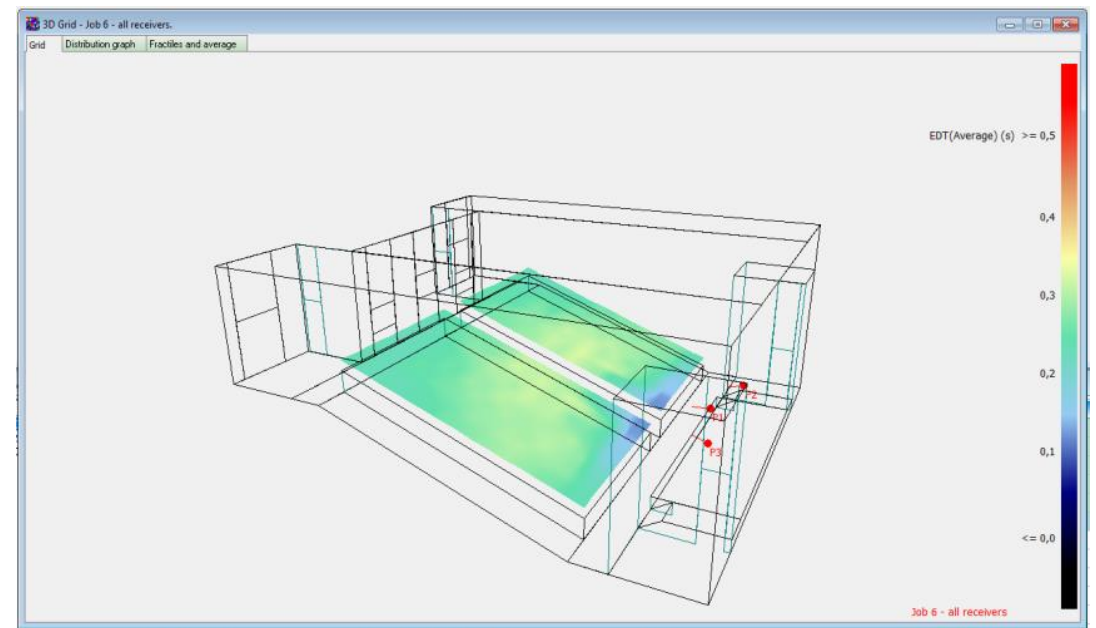

Şekil 10. Konferans Salonu - erken sönümlenme süresi (EDT) parametresinin dağılımı (500 Hz)

\section{$\underline{A-\text { Ağırlıklı Ses Basınc Sevivesi Parametresi }(\operatorname{SPL}(A))}$}

Çizelge 11. Perfore alçı panel için 6 alıcı noktasında A-ağırlıklı ses basınç seviyesi parametresinin değerleri

\begin{tabular}{|c|c|}
\hline SPL (A) & \\
\hline $\mathbf{1}$ & 608 \\
\hline $\mathbf{2}$ & 58,0 \\
\hline $\mathbf{3}$ & 57,5 \\
\hline $\mathbf{4}$ & 56,5 \\
\hline $\mathbf{5}$ & 55,8 \\
\hline $\mathbf{6}$ & 55,1 \\
\hline
\end{tabular}

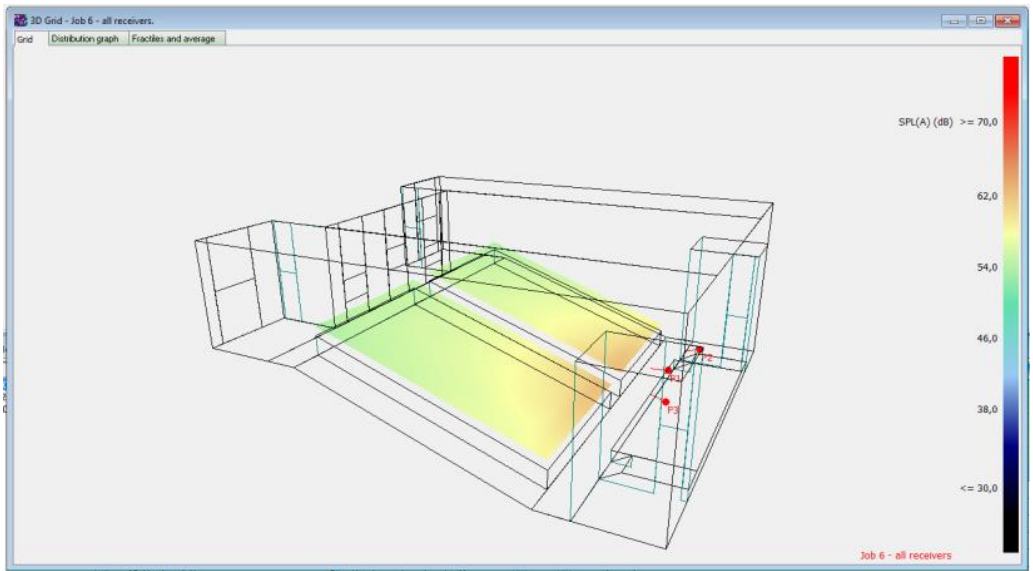

Şekil 11. Konferans Salonu - A-ağırlıklı ses basınç seviyesi (SPL(A)) parametresinin dağılımı

\section{$\underline{\text { Konusmanin Iletim Indeksi Parametresi (STI) }}$}

Çizelge 12. Perfore alçı panel için 6 alıcı noktasında konuşmanın iletim indeksi parametresinin değerleri

\begin{tabular}{|c|c|}
\hline STI & 0,81 \\
\hline $\mathbf{1}$ & 0,76 \\
\hline $\mathbf{2}$ & 0,75 \\
\hline $\mathbf{3}$ & 0,74 \\
\hline $\mathbf{4}$ & 0,76 \\
\hline $\mathbf{5}$ & 0,75 \\
\hline $\mathbf{6}$ & \\
\hline
\end{tabular}




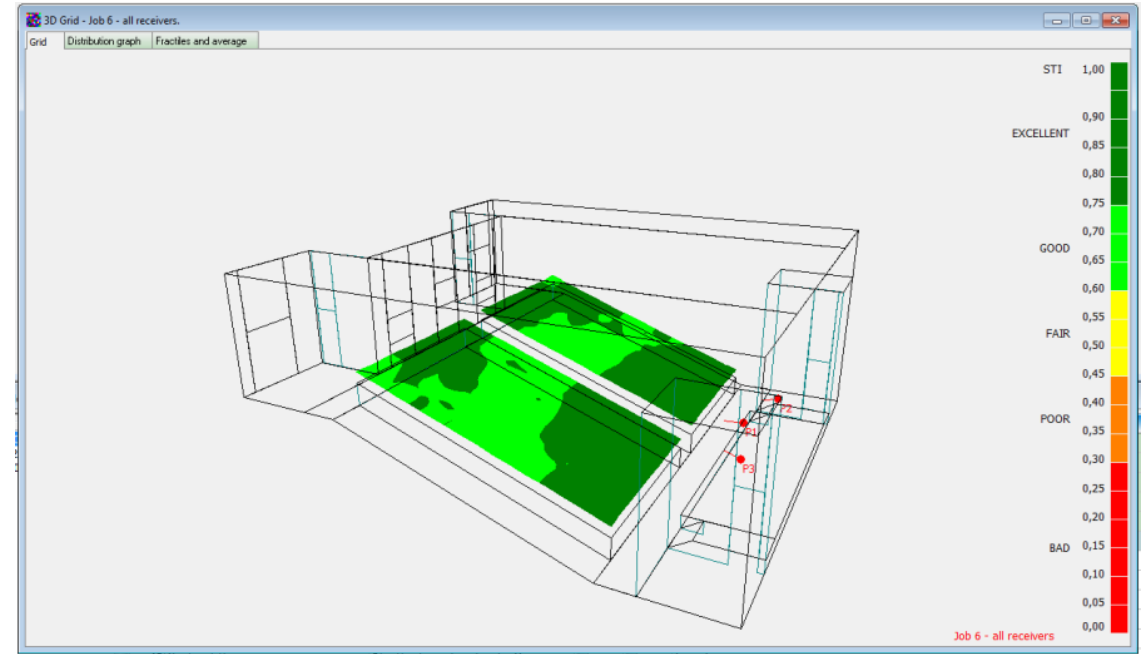

Şekil 12. Konferans Salonu - konuşmanın iletim indeksi (STI) parametresinin dağılımı

\section{Konussmanın Belirginliği Parametresi (D50)}

Çizelge 13. Perfore alçı panel için 6 alıcı noktasında konuşmanın belirginliği parametresi değerleri

\begin{tabular}{|c|c|c|c|c|c|c|c|c|}
\hline $\mathbf{D 5 0}$ & $\mathbf{6 3} \mathbf{~ H z}$ & $\mathbf{1 2 5} \mathbf{~ H z}$ & $\mathbf{2 5 0} \mathbf{~ H z}$ & $\mathbf{5 0 0} \mathbf{~ H z}$ & $\mathbf{1 0 0 0} \mathbf{~ H z}$ & $\mathbf{2 0 0 0} \mathbf{H z}$ & $\mathbf{4 0 0 0} \mathbf{H z}$ & $\mathbf{8 0 0 0} \mathbf{~ H z}$ \\
\hline $\mathbf{1}$ & 0,80 & 0,79 & 0,91 & 0,95 & 0,97 & 0,87 & 0,91 & 0,94 \\
\hline $\mathbf{2}$ & 0,74 & 0,72 & 0,87 & 0,92 & 0,95 & 0,83 & 0,88 & 0,91 \\
\hline $\mathbf{3}$ & 0,71 & 0,70 & 0,87 & 0,92 & 0,96 & 0,82 & 0,87 & 0,91 \\
\hline $\mathbf{4}$ & 0,70 & 0,69 & 0,85 & 0,92 & 0,96 & 0,82 & 0,87 & 0,91 \\
\hline $\mathbf{5}$ & 0,75 & 0,74 & 0,89 & 0,95 & 0,97 & 0,86 & 0,90 & 0,93 \\
\hline $\mathbf{6}$ & 0,71 & 0,70 & 0,87 & 0,95 & 0,97 & 0,86 & 0,90 & 0,93 \\
\hline
\end{tabular}

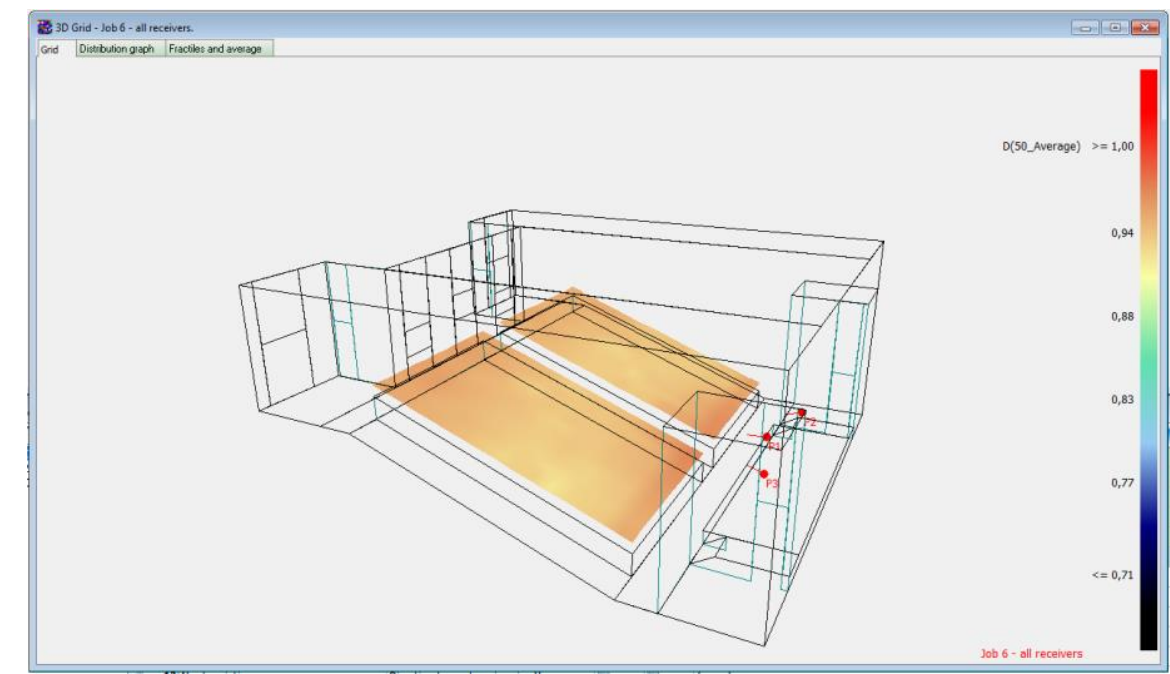

Şekil 13. Konferans Salonu - konuşmanın belirginliği (D50) parametresinin dağılımı (ortalama) 
Parametrelerin minimum, maksimum ve ortalama değerleri aşağıda verilmiştir.
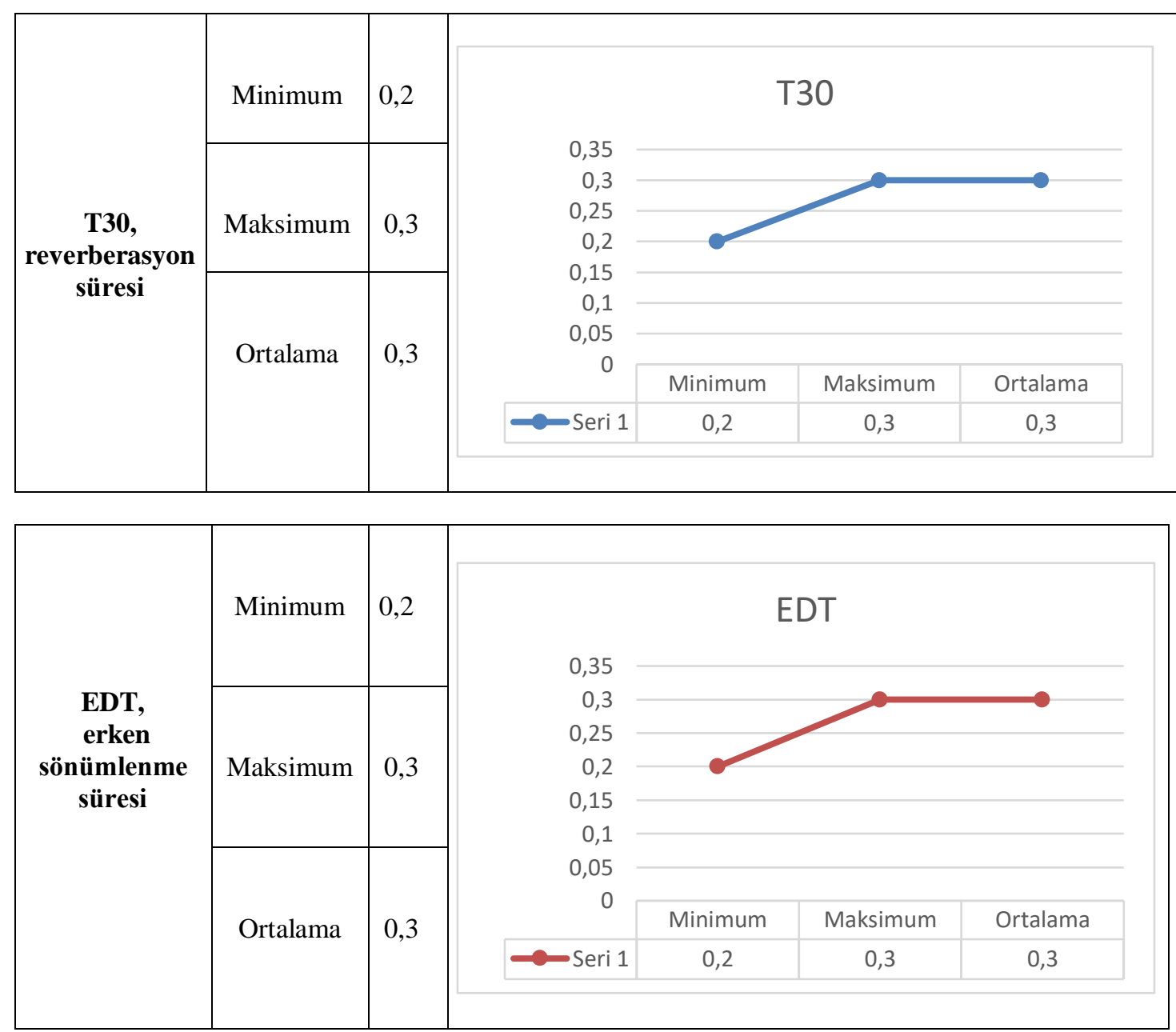

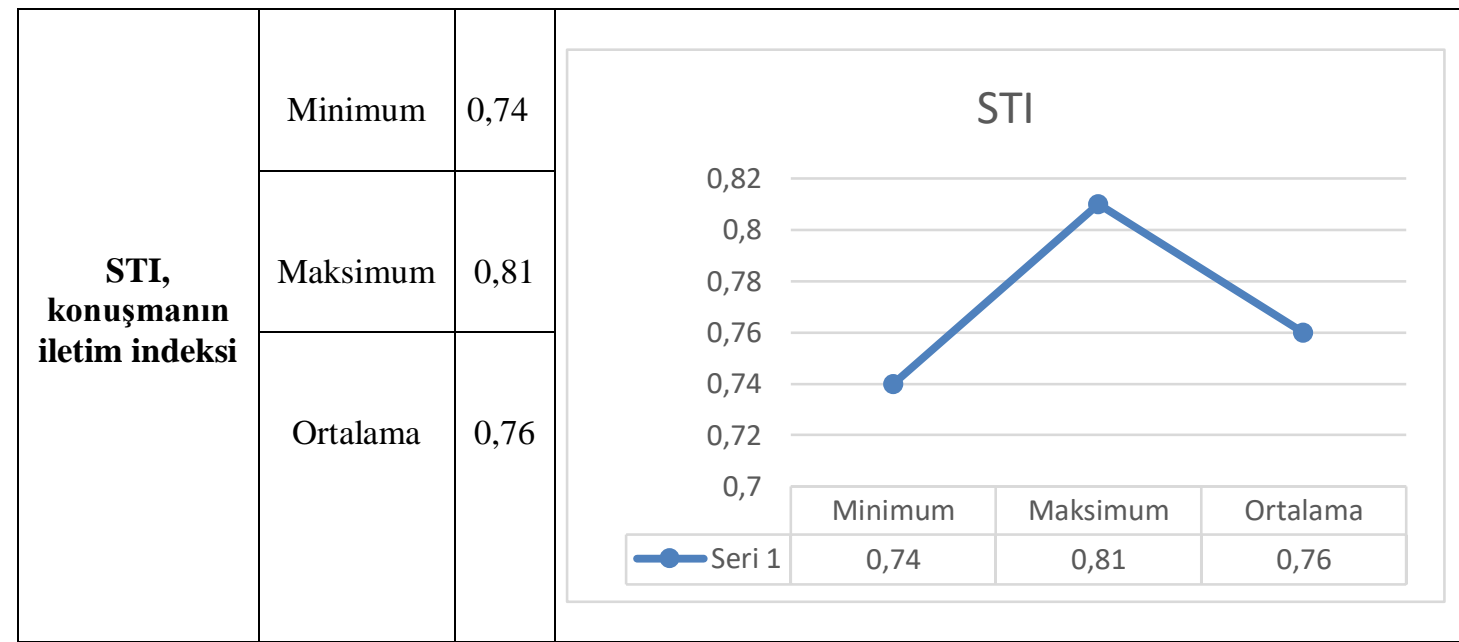



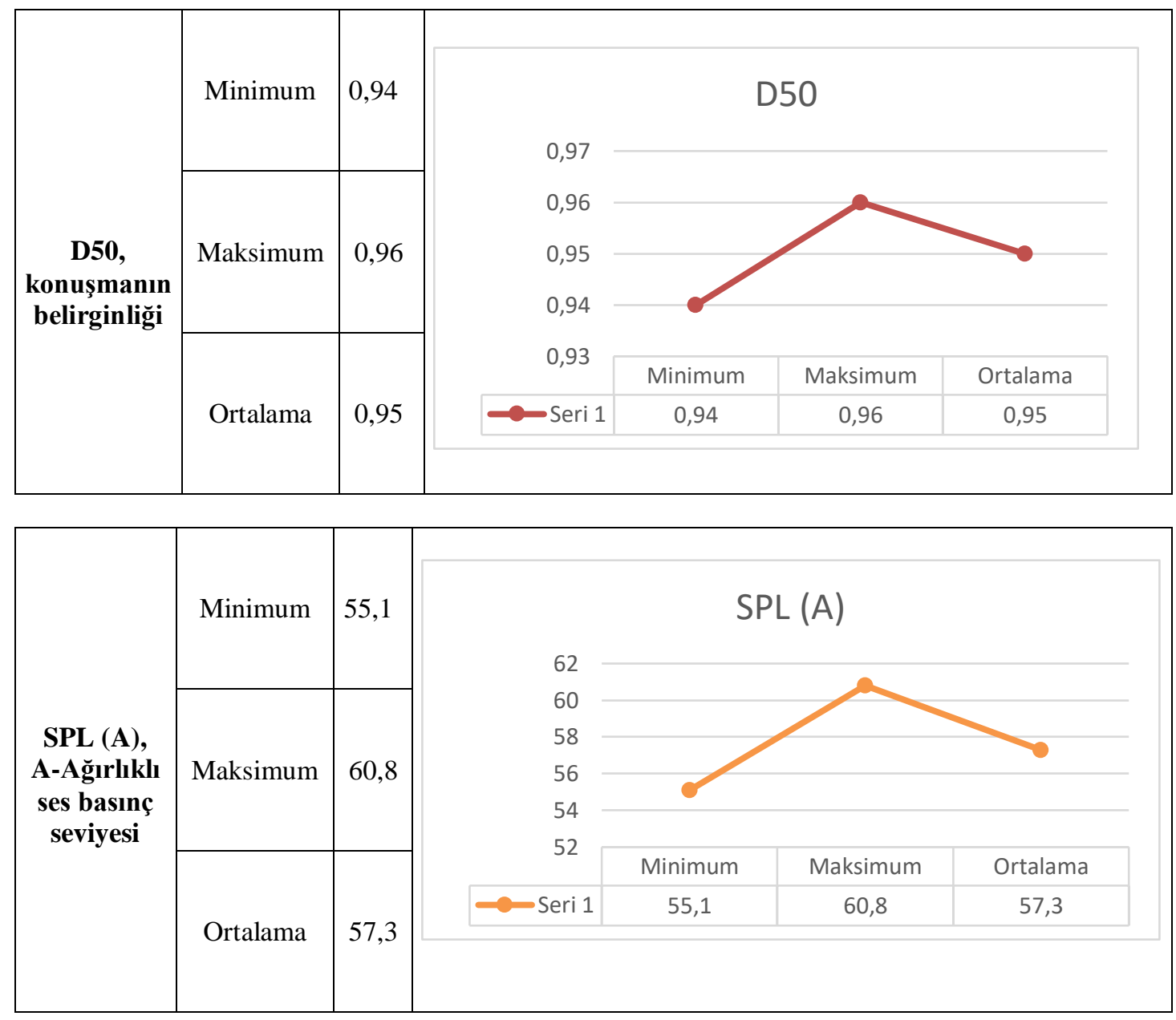

\section{Sonuç ve Değerlendirme}

$\mathrm{Bu}$ çalışma kapsamında; konferans salonu için; projede yer alan ve uygulanmamış olan perfore ahşap panellerin kullanıldığı durum ile mevcut durumda uygulanmış perfore alçı panellerin kullanıldığı durum değerlendirilmiş ve karşılaştırmaları yapılmıştır. Ülkemizde yürürlükte olan yönetmelik, ulusal/uluslararası standartlarda ve literatürde önerilen hacim akustiği parametrelerine göre değerlendirilmiştir.

Çizelge 3.1'de optimum hacim akustiği parametre değerleri ve perfore ahşap/alçı panel kullanım durumu analiz sonuçları tablo olarak verilmiştir. Çizelgede görüldüğü üzere; mevcut salonda uygulanan perfore alçı panel levha ile projede yer alan perfore ahşap panel kullanım durumları değerlendirildiğinde, hacim akustiği parametreleri bakımından birbirine yakın sonuçlar elde edilmiştir. Fakat bu salon için gerekli optimum hacim akustiği değerleri ile kıyaslandığında en önemli parametre olan reverberasyon süresinin, her iki koşul için de istenilen değerin altında kaldığı görülmektedir. Reverberasyon süresi sonuçlarının uygun değer aralığına getirilmesine yönelik olarak; yansıtıcı yüzey kullanımının arttırılması ya da yutucu malzeme kullanımının frekansa bağlı ses yutma katsayıları değerlendirilerek yapılması önerilebilir.

Bu kapsamda ayrıca salon tasarımlarında akustik düzenlemenin proje bittikten sonra analiz edilmesinin uygun olmadığı, akustik tasarım ya da raporun proje aşamasında akustik uzman ile birlikte çalışılarak malzeme kararlarına gidilmesi gerektiği öngörülmektedir. 
International Journal of Scientific and Technological Research

ISSN 2422-8702 (Online), DOI: 10.7176/JSTR/6-01-02

Vol.6, No.01, 2020

Çizelge 14. Konferans salonunun hacim akustiği açısından analiz sonuçlarının değerlendirmesi $[8,9]$

\begin{tabular}{|c|c|c|c|c|c|c|}
\hline $\begin{array}{l}\text { Hacim Akustiği } \\
\text { Parametreleri }\end{array}$ & Optimum Değerler & $\begin{array}{l}\text { Perfore } \\
\text { Ahşap } \\
\text { Panel }\end{array}$ & $\begin{array}{c}\text { Değerlendirme } \\
\text { (Perfore Ahşap } \\
\text { Panel) }\end{array}$ & $\begin{array}{l}\text { Perfore } \\
\text { Alçı } \\
\text { Panel }\end{array}$ & $\begin{array}{l}\text { Değerlendirme } \\
\text { (Perfore Alçı } \\
\text { Panel) }\end{array}$ & $\begin{array}{l}\text { Hissedilen } \\
\text { Fark } \\
\text { (JND) }\end{array}$ \\
\hline $\begin{array}{l}\text { T30,mid } \\
\text { Reverberasyon } \\
\text { Süresi, sn } \\
\text { (Reverberation } \\
\text { Time) }\end{array}$ & $\begin{array}{c}\mathbf{0 , 5 6} \leq \mathrm{T}_{30, \text { mid }} \leq \mathbf{0 , 8 4} \\
(500 \mathrm{~Hz}-1000 \mathrm{~Hz}) \\
{[4,5]}\end{array}$ & 0,40 & $\begin{array}{l}\text { UYGUN } \\
\text { DEĞíL }\end{array}$ & 0,30 & $\begin{array}{l}\text { UYGUN } \\
\text { DEĞiL }\end{array}$ & $\% 5$ \\
\hline $\begin{array}{l}\text { EDT } \\
\text { Erken Sönümlenme } \\
\text { Süresi, sn } \\
\text { (Early Decay Time) }\end{array}$ & $\begin{array}{c}\text { EDT } \leq \text { T }_{30, \text { mid }} \\
(500 \mathrm{~Hz}-1000 \mathrm{~Hz}) \\
{[4,5]}\end{array}$ & 0,30 & UYGUN & 0,30 & UYGUN & $\% 5$ \\
\hline
\end{tabular}

\begin{tabular}{|l|c|c|c|c|c|c|}
\hline $\begin{array}{l}\Delta \text { SPL(A) } \\
\text { Ses Basinç Seviyesi } \\
\text { Farkı, dBA } \\
\text { (Sound Pressure } \\
\text { Level) }\end{array}$ & $\begin{array}{c}\Delta \text { SPL(A) }<10 \mathrm{dBA} \\
{[7]}\end{array}$ & $\mathbf{5 , 4}$ & UYGUN & 5,7 & UYGUN & - \\
\hline
\end{tabular}

\begin{tabular}{|c|c|c|c|c|c|c|c|c|}
\hline \multirow{6}{*}{$\begin{array}{l}\text { STI } \\
\text { Konuşmanın İletim } \\
\text { İndeksi } \\
\text { (Speech } \\
\text { Transmission } \\
\text { Index) }\end{array}$} & $0,75<$ & Çok iyi & $<1,00$ & \multirow{6}{*}{0,75} & \multirow{6}{*}{$\begin{array}{l}\text { UYGUN } \\
\text { DEĞiL }\end{array}$} & \multirow{6}{*}{0,76} & \multirow{6}{*}{ UYGUN } & \multirow{6}{*}{ - } \\
\hline & $0,60<$ & İyi & $<0,75$ & & & & & \\
\hline & $0,45<$ & Orta & $<0,60$ & & & & & \\
\hline & $0,30<$ & Zayıf & $<0,45$ & & & & & \\
\hline & $0,00<$ & Kötü & $<0,30$ & & & & & \\
\hline & & [6] & & & & & & \\
\hline
\end{tabular}

\begin{tabular}{|c|c|c|c|c|c|c|c|}
\hline \multirow{6}{*}{$\begin{array}{l}\text { D }_{50} \\
\text { Konuşmanın } \\
\text { Belirginliği } \\
\text { (Definition) }\end{array}$} & \multirow{6}{*}{$\begin{array}{c}D_{50}>0,50 \\
\text { tüm } \\
\text { frekanslar } \\
\text { [7] }\end{array}$} & $125 \mathrm{~Hz}$ & 0,71 & \multirow{6}{*}{ UYGUN } & 0,72 & \multirow{6}{*}{ UYGUN } & \multirow{6}{*}{$\% 5$} \\
\hline & & $250 \mathrm{~Hz}$ & $\mathbf{0 , 9 3}$ & & $\mathbf{0 , 8 8}$ & & \\
\hline & & $500 \mathrm{~Hz}$ & 0,92 & & $\mathbf{0 , 9 3}$ & & \\
\hline & & $1000 \mathrm{~Hz}$ & 0,90 & & 0,96 & & \\
\hline & & $2000 \mathrm{~Hz}$ & $\mathbf{0 , 8 4}$ & & $\mathbf{0 , 8 4}$ & & \\
\hline & & $4000 \mathrm{~Hz}$ & $\mathbf{0 , 8 4}$ & & $\mathbf{0 , 8 9}$ & & \\
\hline
\end{tabular}

\section{Kaynaklar}

[1] Odeon A/S, "Room Acoustics Modelling Software, V 15.00 Auditorium”, Denmark, (2018).

[2] ODEON Material Library

[3] Mehta, M., Johnson, J., Rocafort, J., “Architectural Acoustics Principles and Design”, Merrill Prentice Hall, 301-306, (1999).

[4] Ahnert, W. and H.P. Tennhardt, "Acoustics for Auditoriums and Concert Halls," in Handbook for Sound Engineers, ed. G.M. Ballou, 4th ed., Elsevier Focal Press, (2008).

[5] Everest, F. A., Pohlmann, K. C., "Master Handbook of Acoustics” McGraw Hill, (2009).

[6] TS EN 60268-16: 2012-01, "Ses sistem cihazlar1-Bölüm 16: Konuşma iletim indeksi ile konuşma anlaşılabilirliğinin tarafsız sınıflandırılması", Türk Standartları Enstitüsü, Ankara (2012).

[7] TS EN ISO 3382-1, "Akustik- Odaların Akustik Parametrelerinin Ölçülmesi - Bölüm 1: Performans Boşlukları”, Türk Standartları Enstitüsü, Ankara (2010).

[8] DEMIREL, F., ÖZÇETİN, Z., EMINEL, M., “Kongre ve Kültür Merkezi Örneğinde Çok Amaçlı Salon Akustiği İncelemesi”, Social Science Development Journal, ISSN 2630-6212, Volume 3 Issue 113, 15.10.2018.

[9] DEMIREL, F., ÍLISULU, G., GÖRKEM, M., (2018). “Acoustic Design of Sivas Cultural Center Multipurpose Hall”, Journal of Polytechnic (E - SCI), 21(3) (535-542). 